\title{
Sexual Harassment Experience Among the Female Population in Bangladesh
}

\author{
Mohammad Iftakhar Parvej", Mimma Tabassum, Mohammad Rasel Hossain
}

Department of Statistics, Noakhali science and Technology University, Noakhali, Bangladesh

\author{
Email address: \\ iftakhar.nstu@gmail.com (M. I. Parvej) \\ ${ }^{*}$ Corresponding author
}

\section{To cite this article:}

Mohammad Iftakhar Parvej, Mimma Tabassum, Mohammad Rasel Hossain. Sexual Harassment Experience Among the Female Population in Bangladesh. Science, Technology \& Public Policy. Vol. 4, No. 1, 2020, pp. 22-26. doi: 10.11648/j.stpp.20200401.14

Received: April 3, 2020; Accepted: April 28, 2020; Published: May 19, 2020

\begin{abstract}
Bangladesh is a south Asian country speaking of which this country is not also free from such inhuman events named sexual harassment. Lack of family governance, lack of law enforcement, abuse of internet, lack of social awareness provokes the offenders to do such unsocial activities. In this basis the study was conducted to uphold the overall scenario of sexual harassment in Bangladesh. This paper includes the students of different institutions, homemaker, worker, employer and maids. The primary data for this study were collected with a predetermined questionnaire within the month of September to November 2019. A number of 489 respondents were interviewed to know about their experience on sexual harassment. The study finds that $91.4 \%$ of the respondents claimed to face sexual harassment at least once in their life where $1.4 \%$ and $12.3 \%$ of them claimed that they were sexually harassed every day and frequently respectively. The study reveals that victims mostly harassed by stranger. The study suggests that offenders are mostly of age group "16-30". The study also compares the sexual harassment rate of Noakhali district with other districts combined where the study shows that the rate in both case is very severe. The study shows that this kind of inhuman wrongdoing generated huge amount of fear in female population. As a result this incident put a great impact on the social life of the respondents. The respondents urged to strict law enforcement process and to raise social awareness about the harassment so that it can help to minimize the sexual harassment nationwide.
\end{abstract}

Keywords: Sexual Harassment, Female, Bangladesh

\section{Introduction}

It is illegal to harass a person (an applicant or worker) due to that individual's sex. Harassment can include "sexual harassment" or unwelcome sexual advances, requests for sexual favors, and other verbal or physical harassment of a sexual nature. Harassment does no longer have to be of a sexual nature, but, and may include offensive comments about a person's sex. For instance, it's miles unlawful to harass a woman by using making offensive comments about women in general. Both victim and the harasser may be either a female or a person, and the victim and harasser can be the equal sex.

Sexual harassment is a global issue taking place in every society. The problem has been spread at every corner of our society very rapidly forming as national problem. Any undesired behavior of sexual nature is known as Sexual harassment that is smaller incident to serious abuse which may be even forced sexual activity that creates an intolerable atmosphere for the recipient. Women are bound to endure inappropriate behavior because they lack of power, social security and fearlessness and associated to endure peacefully. It has far reaching results to the victim, their family and employer organization and different workers. Victims of harassment may develop significant physical, psychological and job-related impacts. According to the definition of sexual violence by World Health Organization (WHO) as: any sexual act, plat to obtain an act, unwanted sexual comments or advances, or acts to traffic, or otherwise directed against a person's sexuality using coercion, by a person no matter of their relationship to the victim, in any setting, including but not limited to home and work [1].

Day by day the rate of sexual abuse against women is increasing around the world. In their childhood around 20 
percent of women have been sexually abused in the world [2]. It is also increasing rapidly in Asian countries. In Japan 60 percent [3] while 25 percent of women in India [4] and in North Carolina, United States 19 percent [5] of women suffer sexual violence. Sexual offence is defined as sexual intercourse or sex-related acts performed in a way which is against the provision of the law [6]. According to the assumed information of WHO about 1.53 million people will be died by 2020 through suicide, which mostly will be occurred in the effect of harassment. In every 20 second minimum one dies and in every 1-2 second minimum one does try to suicide in accordance with this estimate [7]. Although sexual abuses most frequently are by a man on a woman, it may involve any combination of two or more men, women and children [8].

There are three categories of sexually harassing behavior: (i) gender harassment (verbal and nonverbal behaviors that convey hostility, objectification, exclusion, or second-class status about members of one gender), (ii) unwanted sexual attention (verbal or physical unwelcome sexual advances, which can include assault), and (iii) sexual coercion (when favorable professional or educational treatment is conditioned on sexual activity). Harassing behavior can be either direct (targeted at an individual) or ambient (a general level of sexual harassment in an environment) [9].

The aim of our study is to ascertain sexual harassment in and around Noakhali district and to analyze the data with respect to epidemiological and demographics presentation, relationship between victim and accused, kind of sexual harassment experienced most and recommendation to stop this sexual harassment. We also want to collect the information outside the Noakhali district and know the comparison between Noakhali district and outside Noakhali district. We also want to find the overall scenario of Bangladesh about sexual harassment.

\section{Previous Research}

Malovich, N. J. and Stake, J. E. (1990) [10], found the attitudes about sexual harassment were assessed in a group of 224 undergraduate students. Participants responded to scenarios in which a male professor made inappropriate sexual advances to a female student. Participants then completed rating scales and questions concerning attributions of blame for harassment, educational and emotional effects, and strategies for coping with harassment. Participants also provided information as to their own harassment experiences. Women's reported reactions to actual harassment were consistent with their responses to scenarios.

Salman, M., et al (2016) [11] investigate the impact of sexual harassment on employee turnover intention in educational sector of Peshawar, Pakistan. A total of 127 participants are selected from three private and three public sector business schools of Peshawar. The results found the existence of positive relationship between sexual harassment and employee turnover intentions. They suggested that strong interventions to reduce the incidents of sexual harassment in order to retain employees and enable them to work efficiently.

Khan, M. B. U. and Shathi, I. J. (2018) [12] studied a number of 120 female students therefore, interviewed to understand the nature of sexual harassment experienced by them and their intimates. The study finds that most of the students were the victims of such incidents at least for once in their lives and most of them were victimized in the locations that are outside of their educational institutions. For preventing such offensive actions, most of the female students insisted on strict law enforcement process so that it can have a deterrent impact on the society.

\section{Research Method}

The study was conducted between September 2019 and November 2019 among the female students (Noakhali Science and Technology University, Sonapur Degree Collage, Noakhali Girls School) and different job holders, housewives lives in Noakhali and outside Noakhali district.

This was a field study research. In order to collect primary data the questionnaire survey technique was used. A wellstructured questionnaire was designed by the department of statistics of Noakhali Science and Technology University after the intensive review of the literature and practical experience. The questionnaire was pre-tested among the 35 people who did not participate in the study and was modified as necessary. The questionnaire consisted of 17 questions.

Participants were interviewed face-to-face by investigators who were trained before the survey. In case of refusal to participate was dropped. The study is exploratory in nature. Purposive sampling technique was adopted to select samples. The result of this entire study was compute by using Microsoft Excel and Statistical Package for the Social Sciences (SPSS), version-16.

\section{Results}

A manipulation check was done on the perceptions of the scenarios, and we see that $99 \%$ girls know about sexual harassment. In this analysis $91.4 \%$ girls have faced sexual harassment and only $8.4 \%$ of them didn't experience that, $92 \%$ girls have faced sexual harassment in Noakhali district and $89.2 \%$ girls have faced sexual harassment in other districts. Most of the victims $(87 \%)$ are unmarried and maximum (91\%) were students. Among 489 cases we find 439 Muslims, 43 Hindus and 7 Buddhists. We also see that the age between $15-24$ of girls' $(80 \%)$ have faced harassment mostly (Figure 1).

Many girls have faced different kinds of sexual harassment in their daily life. In this case $26.8 \%$ girls faced verbal teasing \& $23.9 \%$ girls faced unwanted touching mostly by harasser. Not only this two types but also there are many more types of harassment they have faced together like lustful staring, intimidating presence. Sometimes sexual harassment is so emerged that girls have victimized nearly rape or raped. We noticed that $1.4 \%$ of the respondent have experienced the sexual harassment everyday (Table 1). 


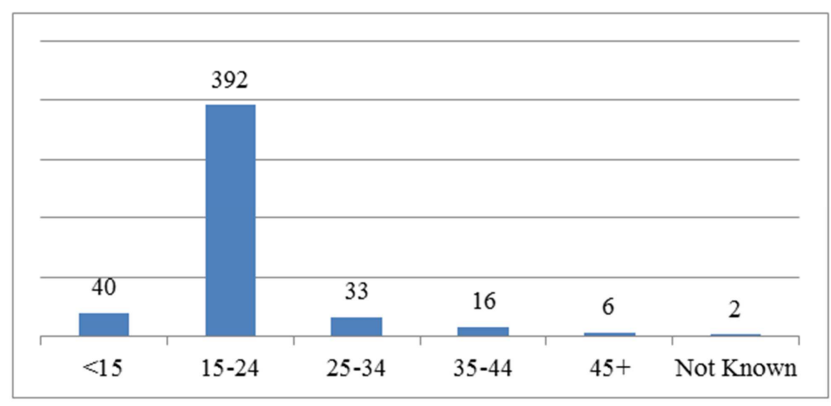

Figure 1. Age group wise distribution of victims.

Table 1. Different Time interval vs. Number of cases.

\begin{tabular}{lll}
\hline Time Interval & No of victims & Percentage \\
\hline Not mentioned & 42 & $8.60 \%$ \\
Everyday & 7 & $1.40 \%$ \\
Frequently & 60 & $12.30 \%$ \\
Rarely & 156 & $31.90 \%$ \\
Sometimes & 224 & $45.80 \%$ \\
\hline
\end{tabular}

Women get harassed in several places including home, work place, market, public transport, street, social media. Most of them were faced the harassment at street and the percentage is $35.4 \%$. Again $19.4 \%$ of harassment is reported at public transport and $3.9 \%$ at market.

Focusing on the factor of harasser, a woman can be victimized by relatives, friend, colleague, stranger, driver, teacher and others. Most of the women are victimized by the stranger $(65.44 \%)$.

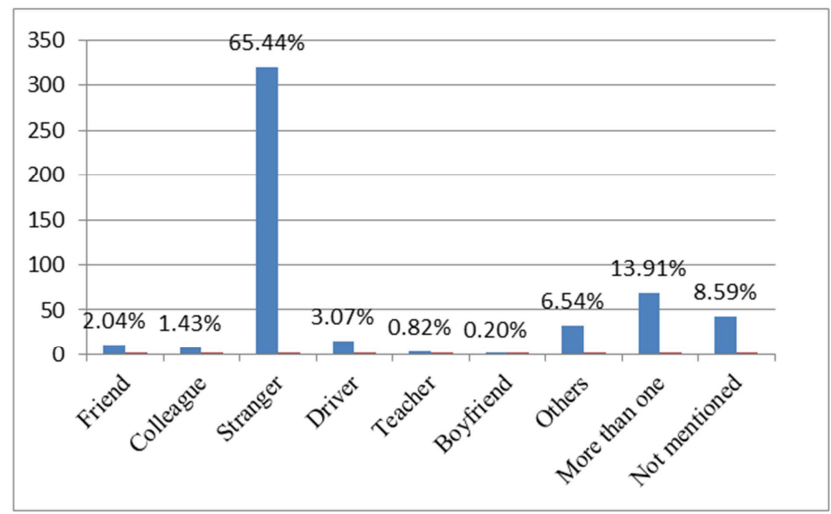

Figure 2. Victims offender relationship.

Women are much more likely to be victims of sexual harassment. Men of different ages harassed women. The person aged 16-30, mostly harassed women (Table 2).

Table 2. Men of different age group harassed women.

\begin{tabular}{lll}
\hline Age Group & No of cases & Percentage \\
\hline $10-15$ & 8 & $1.64 \%$ \\
$16-30$ & 231 & $47.24 \%$ \\
$31-50$ & 160 & $32.72 \%$ \\
$50+$ & 16 & $3.27 \%$ \\
$16-50$ & 32 & $6.54 \%$ \\
Not mentioned & 42 & $8.59 \%$ \\
\hline
\end{tabular}

During harassment women feels afraid, nervous, angry and embarrassed sometimes. We elicited that $36 \%$ of the women got angry and $22 \%$ are nervous (Figure 3).

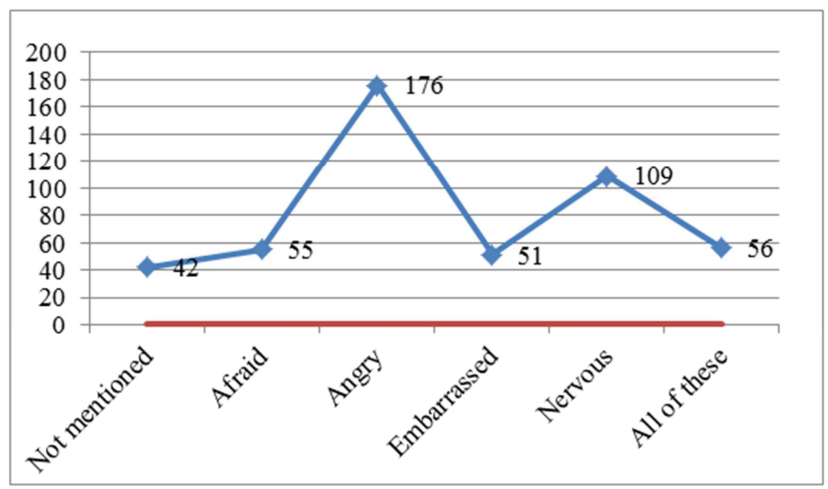

Figure 3. Victims felling when they were harassed.

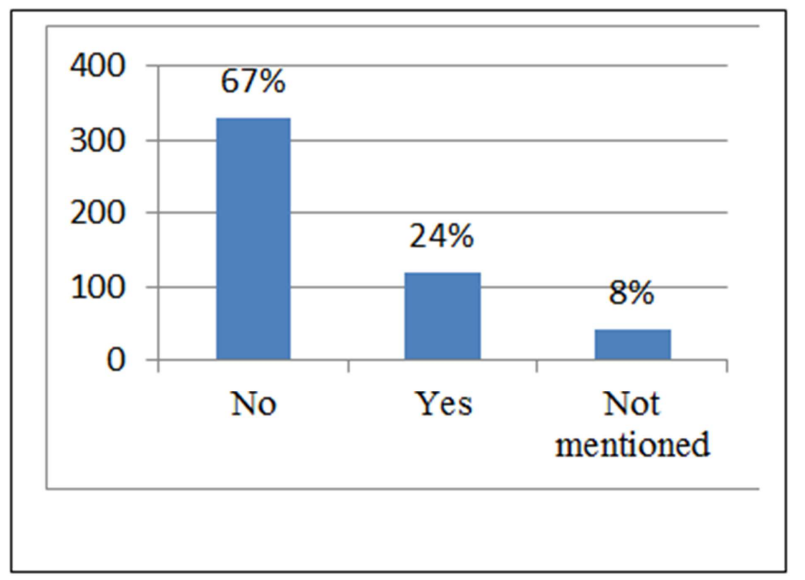

Figure 4. Percentage of victims getting help.

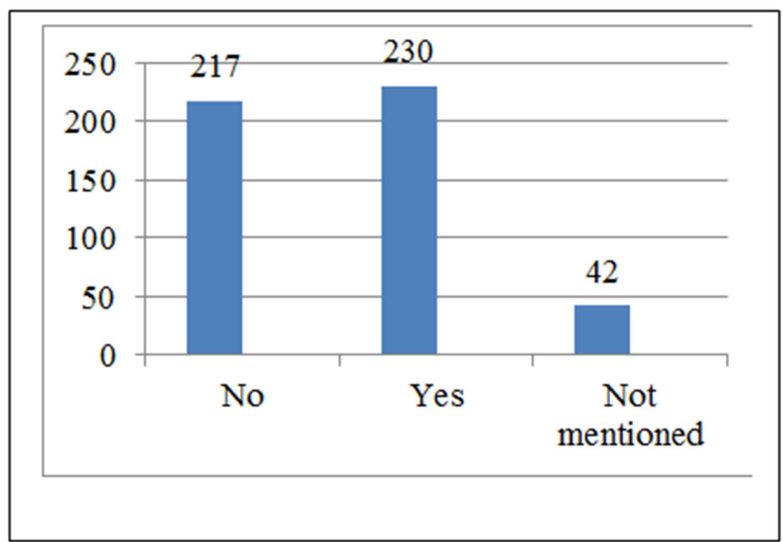

Figure 5. Number of victims informs their family.

As sexual harassment is a big crime only $16.4 \%$ women raised their voice against the crime and tried to protest and $12.7 \%$ women don't know what to do during this pestered. $34.36 \%(18.2 \%+16.16 \%)$ women share with their $\mathrm{F} \& \mathrm{~F}$ (Family + Friend) and $21.27 \%$ women kept quiet. When Sexual harassment can compare as a social malady, only $24 \%$ women get help by surrounding people (Figure 4). From the analysis we can see that $47 \%$ women informed their family about the incident and $44.2 \%$ (Figure 5) didn't even share 
this incident with family and the matter of sorrow is most of the people remained quite after knowing about the incidents only some of them took legal action (Figure 6). As the effect of sexual harassment $10.2 \%$ changed their attire, $10 \%$ changed their route and the noticing part is that a massive portion doesn't act anything (Figure 7), they take the harassment as a part of their normal life.

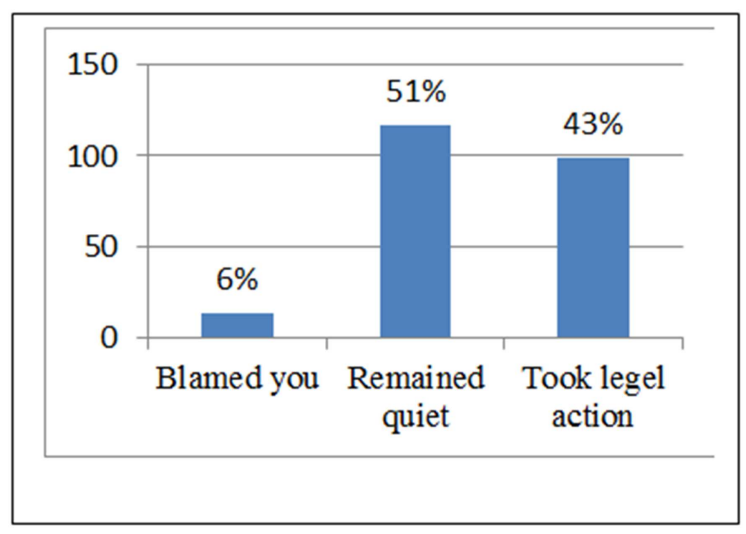

Figure 6. Percentage of victims' action.

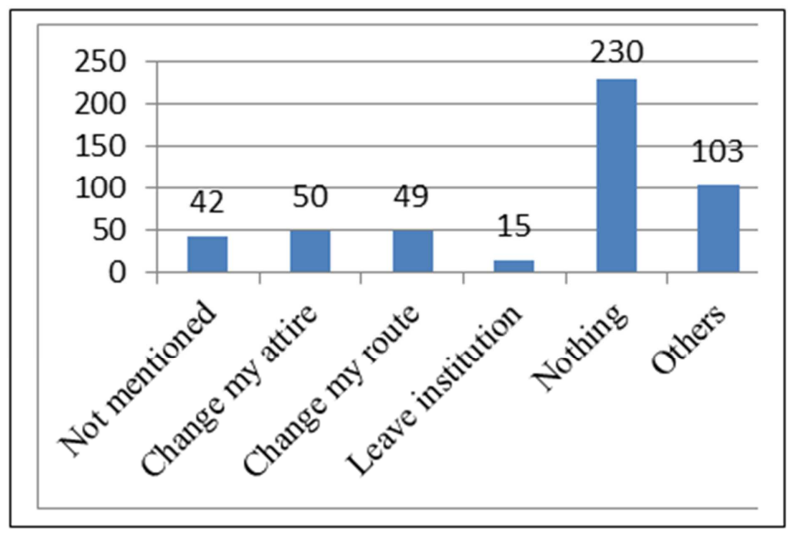

Figure 7. Number of victim's action after harassed.

Table 3. Steps should take to prevent sexual harassment.

\begin{tabular}{lll}
\hline Protection & No of Cases & Percentages \\
\hline Not Mentioned & 42 & $8.59 \%$ \\
Carry pepper spray & 83 & $16.97 \%$ \\
Carry something sharp & 93 & $19.02 \%$ \\
Learn martial art & 114 & $23.31 \%$ \\
Others & 133 & $27.20 \%$ \\
Anything for protection & 24 & $4.91 \%$ \\
\hline
\end{tabular}

In most case (58\%) girls are the victim of mental trauma. This rate is high and it's an alarming rate. Almost $83 \%$ girls' think that our country law in not enough to take legal action against harasser. Due to lack of social awareness, lack of family governance, lack of law enforcement, abuse of internet and drug addiction are liable for sexual harassment is occurring so frequently in Bangladesh. We can suggest that learn martial art is an effective way to prevent sexual harassment on her own as $23 \%$ of the respondents prefer this option (Table 3 ). Carry something sharp, paper spray can also a good option. In our study most of the respondents recommended strict enforcement of law to stop this sexual harassment. They also suggest arising social awareness, family awareness; proper steps taken by government can reduce the sexual harassment.

\section{Discussion}

Sex related cases are increasing day by day in our country, reflecting the Western influence in our society. Sexual violence is one of the most common crimes against women and its data usually comes from police, clinical settings, NGOs and surveys. The relationship between these sources and global magnitude of the problem corresponds to tip of an iceberg. The number of cases of sexual violence could be higher because many victims do not report for the reason that they are ashamed embarrassed or fear of being blamed [13].

Around 94\% women commuting in public transport in Bangladesh have experienced sexual harassment in verbal, physical and other forms, a study has said. The study, conducted by development organization BRAC, identified males belonging to relatively older age group of 41 to 60 years as the major perpetrators who are responsible for $66 \%$ of such incidents [14]. Similarly we found that, 92\% girls have faced sexual harassment in Noakhali district and 89.2\% girls have faced sexual harassment in other districts. But we find the person aged 16-30, mostly harassed women (the study not conducted only in public transport).

Tamuli R. P et al [13] observed India found the $63 \%$ victims were unmarried. Similarly we found in our study that $87 \%$ are unmarried. Parveen in his study in Pakistan found the same result as India of $63 \%$ unmarried victims [15].

Most of the victims were faced the harassment at street and they claim that most of the perpetrators are unknown to them and they got angry at the time of harassmentA small amount of women raised their voice against the crime and tried to protest. More than $75 \%$ women said that they didn't get help. As the effect of sexual harassment some of them changed their attire, route and a massive portion doesn't act anything, they take the harassment as a part of their normal life.

In Bangladesh sexual harassment was made punishable by Section 10 of the Nari O Shish Nirjaton Domon Ain (2000) states that "if a man, with a view to fulfilling his illegal sexual desire outrage a woman's modesty or makes erotic gesture, such act of the man will amount to sexual harassment". A rigorous imprisonment ranging from 2 to 7 years and additionally an indefinite amount of fine is rewarded for this offence [16].

Due to lack of social awareness, lack of family governance, lack of law enforcement, abuse of internet and drug addiction are liable for sexual harassment is occurring so frequently in Bangladesh. Almost one-fourth of the women suggest that learn martial art is an effective way to prevent sexual harassment.

\section{Summery and Concluding Remarks}

Sexual harassment interrupts the women's rights, 
diminishes their individual freedom and the right of independent mobility, shortens their education lives, upsets their mental health and disrupts them from personal and national development stream. The suicide tendency of women has been increased because of the undesirable condition like sexual harassment. Most of the women said that government should enforce the law on harassing, every parents should be aware of their children's movement and gives them moral education, arise social awareness, Improvement of mentality of men and arise family awareness to stop sexual harassment. We should raise our voice instead of remaining silent against harasser. Every parent should support their girls after facing harassment to prevent suicide tendency. Sexual harassment is a social crime. It's a curse for our society. And this curse can be removed through public concern. If anyone can raise voice against this social crime then everyone will take an affirmative action against it by seeing him/her. So we should take proper steps in every sectors of Bangladesh both publicly and privately to remove this social crime.

\section{Acknowledgements}

We warmly thank the first batch (session: 2016-2017) student of the Departments of Statistics of Noakhali Science and Technology University, Noakhali, Bangladesh for their assistance.

\section{References}

[1] Organization, W. H., World report on violence and health. Geneva: WHO, 2002. WHO Technical Report Series, 2002. 866.

[2] Krug, E. G., et al., The world report on violence and health. The lancet, 2002. 360 (9339): p. 1083-1088.

[3] Niaz, U., Violence against women in South Asia, in Violence against women and mental health. 2013, Karger Publishers. p. $38-53$.

[4] Babu, B. V. and S. K. Kar, Domestic violence against women in eastern India: a population-based study on prevalence and related issues. BMC public health, 2009.9 (1): p. 129.

[5] Cloutier, S., S. L. Martin, and C. Poole, Sexual assault among North Carolina women: Prevalence and health risk factors. Journal of Epidemiology \& Community Health, 2002. 56 (4): p. $265-271$.
[6] Nandy, A., Principles of forensic medicine including toxicology. 2010: New central book agency.

[7] Organization, W. H. Mental health. 2020, Jan 20; Available from: https://www.who.int/mental_health/en/.

[8] Mant, K., Taylor's Principles and Practice of Medical Jurisprudence Thirteen Edition. Churchill Livingstone, Edinburgh London and New York, 1984.

[9] Johnson, P. A., S. E. Widnall, and F. F. Benya, Sexual Harassment of Women: Climate, Culture, and Consequences in Academic Sciences, Engineering, and Medicine 2018. 2019.

[10] Malovich, N. J. and J. E. Stake, Sexual harassment on campus: Individual differences in attitudes and beliefs. Psychology of Women Quarterly, 1990. 14 (1): p. 63-81.

[11] Salman, M., F. Abdullah, and A. Saleem, Sexual harassment at workplace and its impact on employee turnover intentions. Business \& Economic Review, 2016. 8 (1): p. 87-102.

[12] Khan, M. B. U. and I. J. Shathi, Nature of Sexual Harassment Against the Female Students of Bangladesh: A CrossSectional Study in Tangail Municipality. International Journal of Social and Administrative Sciences, 2018.3 (2): p. 73-82.

[13] Tamuli, R., B. Paul, and P. Mahanta, A statistical analysis of alleged victims of sexual assault a retrospective study. Journal of Punjab Academy of Forensic Medicine \& Toxicology, 2013. 13 (1): p. 7-13.

[14] Tribune, D. Study: 94\% women victims of sexual harassment in public transport. 2018, March 7; Available from: https://www.dhakatribune.com/bangladesh/crime/2018/03/07/ study-94-women-victims-sexual-harassment-publictransport $/ ?$ cf chl jschl tk $=\mathrm{a} 435 \mathrm{f} 4 \mathrm{~d} 3 \mathrm{a} 37 \mathrm{a} 2 \mathrm{c} 99 \mathrm{edbf66b} 65$ e9c45678d $\overline{09} \mathrm{c} \overline{\mathrm{d}} 7 \mathrm{c}-15856 \overline{4} 7 \overline{77}-0$ -

AZg5ZX9fAsWhJfs4i7L1ToUq_s1d90tPSmH20qLjNwzJTnwpE27_gWtlDFizuTWyOTHL_hv7CujonMSeOO5EO183HVcMwdfXcRvc0KSkaiXwpYWaNFq5MYDpnuKR 2MqMI_yM25Ff0xabeDD07RCFhlUU0T22poJo3GgDU6cd HW-

rdAnzu7m7tmquORM_b2WgeiL8nv5fRRGQt17tO6dx84VSO a9mc6LcEABEbjWYNZg4OwHhzUcYL 53jpF08Q6IuuEl50ERsOssmEukKRmJFoj0mIixfwrzvBvNyVCocf TPACHfogQ2ieAbIsbu-IZgdRZQRGsc6mZZCgSMKu6RRr3Erp7iwJDYm_rjhrSaHsf9o4e9IW4d91szGTd0m2ZmFH rKUEQTrOli_EPaLk.

[15] Parveen, H., et al., FEMALE VICTIMS OF SEXUAL VIOLENCE. The professional medical journal, 2010. 17 (04): p. $735-740$.

[16] Jurists, T. L., IS THERE ANY LAW ACCORDING TO BANGLADESHI JUSTIFICATION. 2020, 16 February. 